\title{
THE ROLE OF THE VESSELS IN OSTEOGENESIS*
}

\author{
J. TRueta, Oxford, England \\ From the Nuffield Orthopaedic Centre, Oxford
}

\begin{abstract}
We have now an immensely greater knowledge of the factors involved in bone formation than was available to Albrecht von Haller when he made the then extravagant suggestion that the vascular system was responsible for osteogenesis. In his book Experimentorum de ossium formatione (1763) he stated that " the origin of bone is the artery carrying the blood and in it the mineral elements" and had the courage of opposing Duhamel de Monceau's periosteal theory of bone formation. For, he wrote, "vessels are found in the cartilage and without any doubt they are shown in the periosteum by the injection of coloured fluids." Thus, even in the periosteum the vessels were considered by Haller to be responsible for laying down bone. Haller's conviction soon found a supporter of the calibre of John Hunterprobably about 1754-as shown in the first edition of his collected works (1835). Despite the great authority of the initiators of the vascular theory it fell into disrepute and subsequent oblivion owing to the combined efforts of many influential men who, like Duhamel (1742), Syme (1840), Flourens (1842) and Ollier (1867), made the periosteum responsible for bone formation. To these opponents men like Goodsir and Goodsir (1845), Gegenbaur (1864) and Macewen (1912) were added, among many others who devoted their attention to the role of the osteoblast in the origin of bone and forgot all about the vessels. The more recent contributions by Leriche and Policard (1926), despite bringing the blood into the osteogenetic picture for the first time in a century and a half, unfortunately relegated the osteoblast to a secondary role and were unable to restore the interest of research workers in the study of the role of the vascular system in osteology in general and osteogenesis in particular.

This lack of interest, at a time when so many works are being dedicated to a study of the histochemical structure and physical properties of bone, may be explained by the extreme difficulty of investigating the vasculature of a tissue as hard as bone-a tissue with such disproportion between the moderate number of afferent arteries and the large number of efferent veins that it prevents the taking of representative samples of venous blood to investigate gradients of oxygen tension and other information required for a study of blood flow.

For these and other reasons the study of the vasculature of bone has been done mainly on histological sections which are unrepresentative of the characteristics of the vascular system in vivo. This seems the main reason for the general lack of interest in this field. An indication of the technical difficulties encountered in these investigations is shown by the fact that many workers illustrate their views by drawings and diagrams rather than by photographs of their material.
\end{abstract}

\section{VESSELS IN BONE}

In this paper we summarise our main findings during the fifteen years we have been studying the vasculature of bone. Some of this material has already been published. Some is still in course of publication or preparation. Conscious of the impossibility of establishing the rate of blood flow without an appropriate knowledge of the anatomical details of the bone vessels, we have largely concentrated on recording the number, shape, size and relationship of these vessels in laboratory mammals and in man, for we believe in the dictum

* Lecture given at the Gordon Conference on the Chemistry, Physiology and Structure of Bones and Teeth, Meriden, New Hampshire, United States of America, on July 11, 1961. 
of Claude Bernard that anatomy is part of the basic knowledge that the physiologist must master. Our technique of vascular visualisation was developed from that originally used to study the changes in calibre of the peripheral vessels during experimental traumatic shock (Barnes and Trueta 1942). A much improved method was developed for the study of the renal circulation (Trueta, Barclay, Daniel, Franklin and Prichard 1947) whereby microradiography after vascular perfusion was introduced. Thorotrast, colloidal silver and a barium sulphate suspension (Micropaque) were extensively used (Barclay 1951). We owed to Professor E. C. Amoroso in 1948 the adaptation of the Spalteholz technique of inducing tissue transparency in the study of the vasculature of bone.

We use a perfusion medium which will allow both microradiographic and photographic studies to be carried out and which will not prevent the preparation of fine sections for histology - namely a mixture of equal parts of Micropaque and a 2 per cent aqueous solution of Berlin blue. This medium fills the whole of the vasculature of bone including the capillaries and sinusoids. When only photographs are required, colloidal India ink also gives adequate demonstration. For fine histological and vascular details alternate thin (8-10 $\mu)$ and thick $(200-400 \mu)$ sections are used. The first results with these methods were published some years ago (Trueta 1953; Trueta and Harrison 1953; Harrison, Schajowicz and Trueta 1953). At the present time these methods, or small modifications of them, are used by a number of investigators with generally satisfactory results.

The obvious limitation of perfusion procedures alone compelled us to add electron microscopy, microscopy with ultra-violet light using fluorescent bone markers, tissue culture, autoradiography with tritiated thymidine and x-ray diffraction to come close to the depths of the osteogenetic problem. Unfortunately we have so far been unable to devise an accurate method of measuring the rate of blood flow in bone. So far only the bone marrow cavity has been studied after atraumatic puncture, for the venous blood refuses to be collected outside the bone; in this, bone cannot compare with the liver, the kidney or the lungs-organs where venous outflow studies are easily performed.

\section{RELATIVE IMPORTANCE OF THE SEVERAL SOURCES OF BLOOD TO BONES}

The accumulation of anatomical details of vessels, and of the effect on the bone of the suppression of any one of the intra-osseous systems of vessels-nutrient, metaphysial, epiphysial and periosteal-has allowed us to establish what we believe to be a fairly accurate picture of the circulation in bone. Most of the studies have been in the rabbit, the guinea-pig, the dog and the rat, but man has also been the object of study (Trueta and Harrison 1953, Trueta 1957, Waugh 1958, Wiley and Trueta 1959, Claffey 1960, Brodetti 1960). The long bones receive their arterial blood flow from four sources.

The nutrient artery-Usually there is only one, but in the human femur there are often two. This is responsible for more than 50 per cent of the total blood supply of the long bones, and occasionally perhaps as much as 70 per cent of it. It provides the blood for the whole of the shaft of the long bones up to the epiphysial cartilage during growth, and is the main source of blood for the large sinusoidal system of vessels in the bone marrow. The nutrient artery is the one mainly responsible for filling the bone veins either directly by the capillaries or through the sinusoidal network.

The perforating arteries of the metaphysis and epiphysis-Before the end of growth, the vessels of the epiphysis are unconnected with those of the metaphysis except for a few superficial anastomosing branches. Later they become intimately anastomosed with each other and with branches from the nutrient artery. We believe that they contribute from between 20 to 40 per cent of the total blood supply to the bone.

vol. 45 B, NO. 2, MAY 1963

$\mathbf{L}$ 
The periosteal vessels-This is the most difficult system of vessels to estimate correctly because most of the superficial cortical vessels remain empty of the perfusion medium in the majority of specimens, a fact that has misled some people into believing that no periosteal arteries penetrate the cortex (Macnab 1958; Brookes, Elkin, Harrison and Heald 1961). After perfusion of over two thousand mammals we know of the difficulties in showing up these fine capillaries and arterioles and of studying them by perfusion methods alone. For this reason our views on this subject are based on methods less crude than a simple perfusion, such as electron microscopy (Figs. 1 and 2) and ultra-violet microscopy. The most recent information has come from the study of the areas of ischaemia following vascular suppression of each of the four sources of arterial blood to the long bones. We have described some of our findings elsewhere (Trueta and Cavadias 1955, Cavadias 1958), showing that the interruption of the bone marrow circulation by occlusion of the nutrient artery and the metaphysial vessels caused necrosis of the inner two-thirds of the cortex, whereas the outer third remained alive.

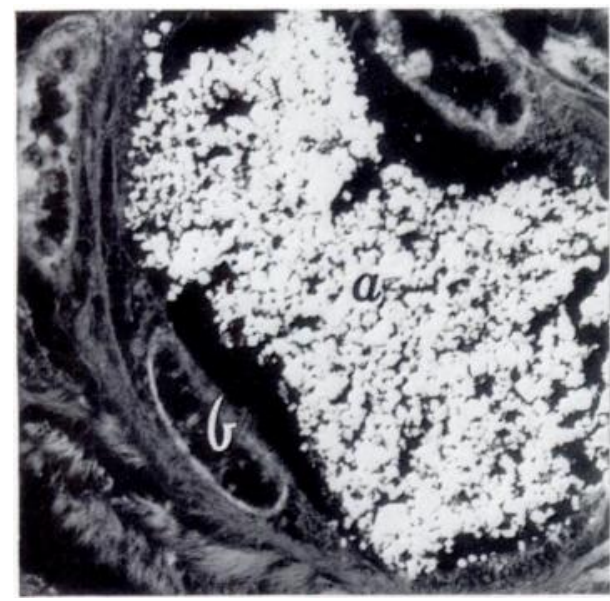

FIG. 1

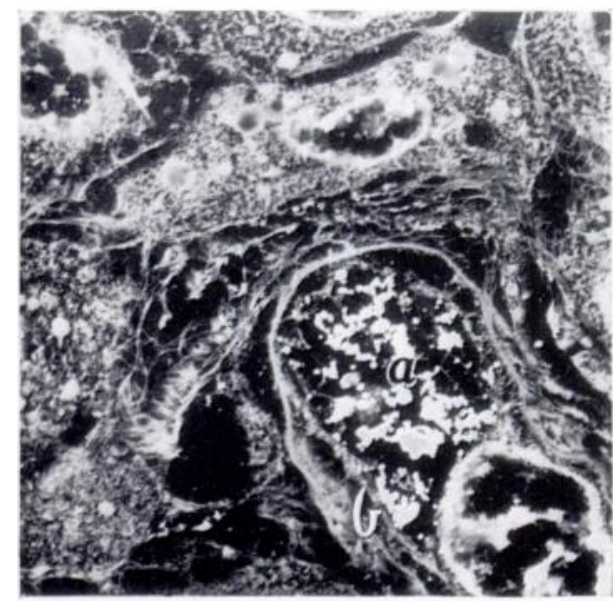

FIG. 2

Electron microscope photograph. Rabbit. Figure 1-Vessel perfused with Micropaque, large enough to be observed by the optical microscope. Figure 2 -Small perfused vessel which would be seen with difficulty by the optical microscope. $a=$ vessel; $b=$ endothelial cell. $(\therefore 3,000$.)

Foster, Kelly and Watts (1951) had reached similar conclusions. Experiments suppressing the periosteal blood flow confirmed these findings, for the lifting and isolation of the periosteum from the cortex by a sheath of polythene resulted in the death of approximately the outer third of the cortex. Considerable differences were found between the reparative process in young and adult animals after vascular interruption, but the extent of bone damage caused by suppression of the periosteal circulation was about the same, irrespective of age.

These findings were further confirmed by the examination of a large number of thick celloidin sections of cortex. In the best perfused specimens, vessels crossing the cortexprobably veins - were seen in profuse numbers. None the less, side by side with these presumably outgoing vessels other vessels penetrating the cortex from its outer surface were also observed. We believe these to be capillaries and precapillaries carrying arterial blood from the bone surface to the depths of the cortex. In transverse sections microscopy under ultra-violet light after the injection of tetracycline shows that these are periosteal vessels entering the cortex (Fig. 3) and electron microscopy adds further confirmation of this. Ultra-violet microscopy shows the penetration of the fluorescent substance carried by two vessels in a single canal, these being clearly outlined by the fluorescent ring, a finding confirmed by electron microscopy (Fig. 4). With the help of this technique the characteristics of these two vessels may be seen, one smaller than the other, strongly suggesting that the first 
carries arterial blood while the second is a vein (Fig. 5). All these findings support the view that, at least in a number of Haversian canals, blood flows in both directions and not only outwards.*

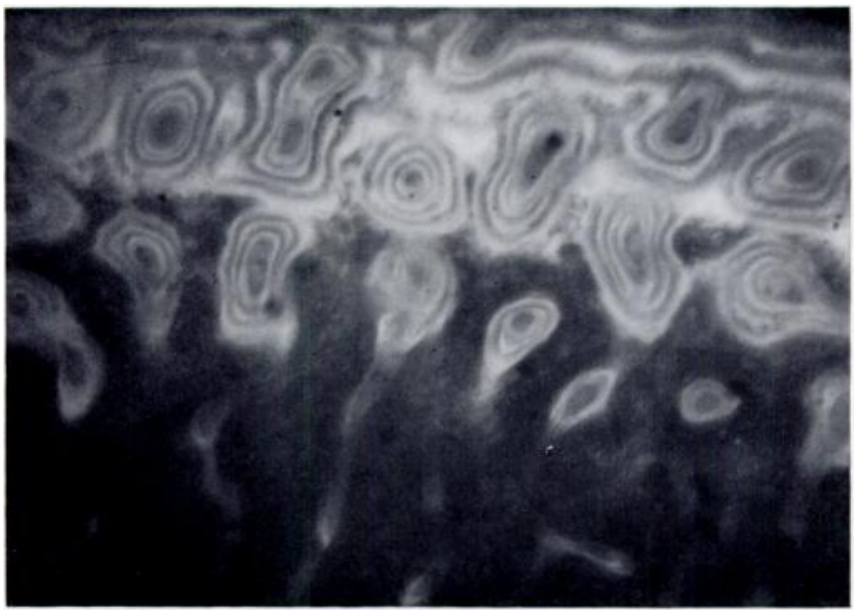

Fig. 3

Photomicrograph obtained by ultra-violet light after the administration of tetracycline and vascular perfusion with Berlin blue. It shows the profuse vascular penetration from the periosteum and of the outer third of the cortex. Fast-growing rat. $(\times 100$.

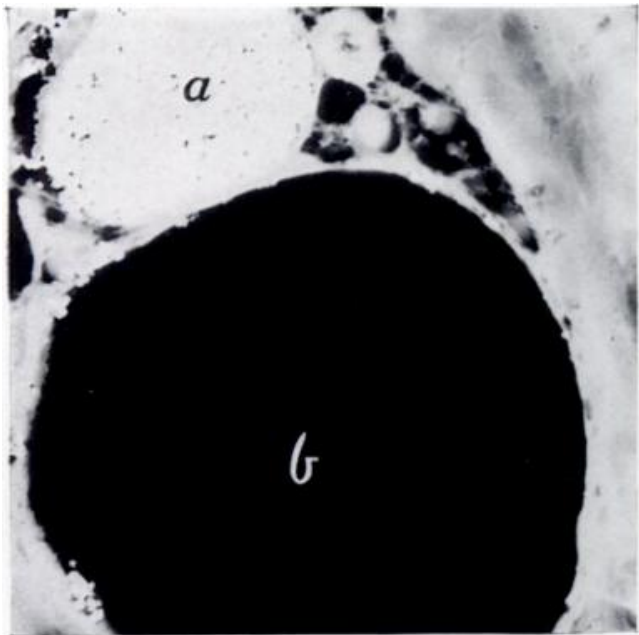

FIG. 4

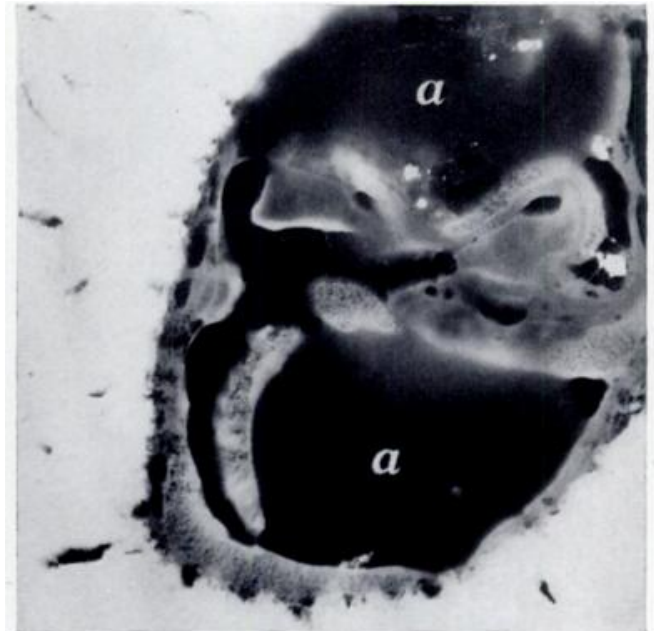

Fig. 5

Figure 4-Electron microscope photograph. Rabbit. Small vessel at the top of a Haversian canal perfused by Micropaque immediately in contact with another much larger empty vessel. $a=$ perfused vessel; $b=$ empty vessel. $(\times 2,100$.) Figure 5 -Haversian canal with two empty vessels at $a, a .(\times 2,500$. $)$

\section{MECHANICS OF THE BONE CIRCULATION}

Various considerations, including clinical ones, made us believe that the intra-osseous circulation cannot be efficiently carried out by the heart pump alone. As we have explained elsewhere (Trueta 1959), the interposition of the sinusoidal system of vessels between the arterioles and the veins within the rigid compartments of the bone marrow (Trueta and

* When this paper was ready to be read at the Gordon Conference, Brookes et al. (1961) claimed that there is only outward blood flow across the cortex, no periosteal arterial supply having been seen to enter the cortex in their perfusion preparations. The fact that they were unable to visualise these periosteal vessels by the method they used does not invalidate the large number of specimens in which the vessels are clearly seen or demonstrated by the four techniques mentioned.

vol. 45 B, NO. 2, MAY 1963 
Harrison 1953) causes such a drop in the cardiac vis a tergo in the veins leaving the bone that, without other contributing factors, the circulation in bone would come to a standstill. Of all these factors the most outstanding is the repeated, intermittent contraction of the muscles adjacent to or attached to the bone. The influence of muscle activity on the bone circulation was suspected by Blair (1938), but we could not find any experimental contribution in the literature showing the relationship between muscle inactivity and sinusoidal and venous engorgement in bone when we published our first contributions (Trueta 1956a, Geiser and Trueta 1958). By surgically suppressing the capacity of the gastrocnemius of the rabbit to contract, we caused impressive sinusoidal and venous engorgement, with rapid and severe rarefaction of the calcaneum (Fig. 6). This observation was complemented by the finding that the venous engorgement ceased and new trabeculae were laid down soon after muscle action was restored.

Many workers have studied the part that muscle tonus and muscle contraction play in propelling the venous blood towards the right auricle, and Wood Jones (1917) mentioned
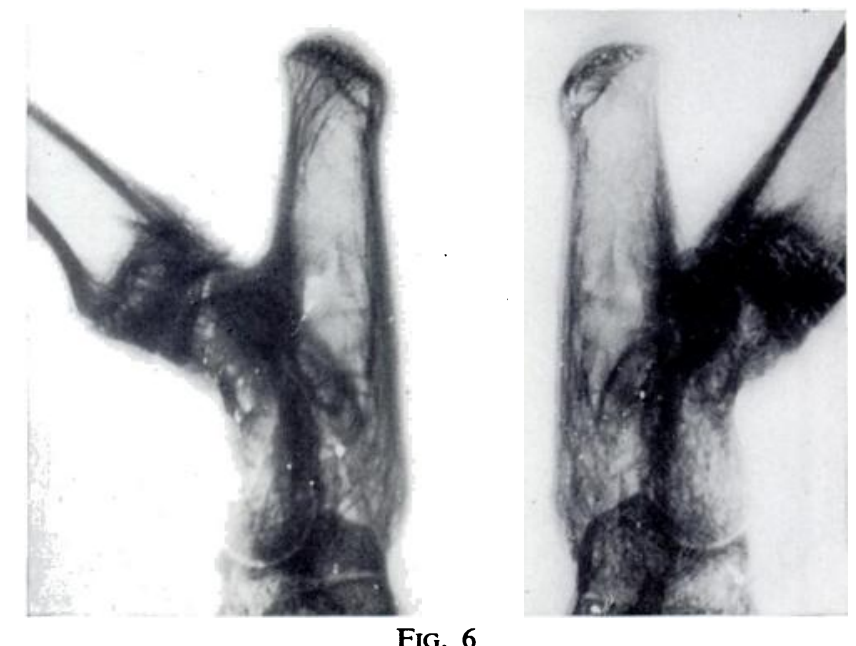

By the resection of about an inch of calcaneal tendon of the rabbit three weeks before, severe bone resorption has been caused in the calcaneum (right of picture).

that, with the muscles at rest, the venous system of the limbs contains a maximum of blood which tends to stagnate in the intramuscular veins. Henderson, Oughterson, Greenberg and Searle (1934) believed muscle tonus to be the third major mechanical factor in the circulation of the blood.

The close relationship between muscle inactivity and bone removal accompanied by venous engorgement suggested that in Sudeck's atrophy the lack of muscle action must be a causative factor. Oedema, which is another element in Sudeck's bone atrophy, is also explained by the inhibition of muscle action as shown by the work of Drinker and Field (1933) and by our own results (Barnes and Trueta 1941). Recent work in the rabbit has shown the importance of the connections between the vessels of the muscle insertions and those of the periosteum (Zucman 1960). Esteve (1957) had already studied in our laboratories some of the changes caused in bone by the vascular shrinkage accompanying paralytic poliomyelitis.

All these factors allow us to stress that proper muscle activity is the best method yet available for maintaining an appropriate blood supply to the bones and that the mechanism of bone deposition and bone removal is intimately linked with the local circulation. Muscle paralysis or even relative muscle inactivity elicits bone resorption (as in poliomyelitic paralysis, flaccid paraplegia, osteoporosis after fracture, plaster immobilisation, etc.) and muscle 
over-activity causes bone deposition (as in spastic paraplegia or even in the bone sclerosis accompanying the muscle spasm of severe osteoarthritis of the major joints). An example of the influence of muscle contraction on the systemic circulation may be seen in the pumping effect of the diaphragm upon the blood in the vena cava (Franklin 1937).

It is not yet clear in what way the local changes of the circulation stimulate either bone removal or bone formation.

The importance of oxygen is shown by the work of Mendlowitz and Leslie (1942). By anastomosing the pulmonary artery to the left auricle in dogs they were able to cause periosteal bone formation characteristic of the pulmonary hypertrophic osteoarthropathy of Pierre-Marie. The enhanced cardiac output was responsible for causing an increased blood flow to the bones and thus of the oxygen available to the marrow in the course of time. This has been confirmed recently by Ginsburg (1958) who found that the blood flow increased in the forearm and the calf of fourteen out of eighteen patients with osteoarthropathy investigated. The recent work of Vaes and Nichols (1962) suggests that when the supply of oxygen to the bone cells is cut off synthesis of new organic matrix ceases.

Further work on this most important field of biochemistry is required, especially if we believe that bone formation and bone removal are not, in the first instance, the result of cell activity but rather depend on the rate and other characteristics of local blood flow and on the behaviour of the vessels themselves.

\section{THE THEORY OF INDUCTION IN OSTEOGENESIS}

It is now over twenty years since Levander (1938) asserted that an unknown substance elaborated by the tissues was responsible for initiating the osteogenetic process. Since then contributions by Annersten (1940), Willestaedt, Levander and Hult (1950), Lacroix (1951), Urist and McLean (1952) and Bridges and Pritchard (1958) have added support to this view, but we have no knowledge of the nature of this substance or even whether it actually exists.

Work done in our laboratory supports Bridges and Pritchard's (1958) findings and conclusions. We believe that the dying or suffering chondrocytes, osteocytes and endothelial cells are responsible, either by their action or by their inhibition, for the liberation of the osteogenetic substance. Bridges and Pritchard (1958) suggested that it may be a protein.

Of one thing we are certain, namely that such a local substance operates directly on the vascular system causing an angioblastic specific stimulation on the bone vessels of the same individual, less on those of the same species, and hardly any on those of the individuals of different species. Work in our laboratories on the vascularity of bone grafts supports these views (Stringa 1957, Trueta 1960, Lima 1961, Deleu 1962). From now on we will call this unknown substance the vascular stimulating factor (V.S.F.).

In a series of experiments in growing laboratory animals we have studied the vascular participation in the natural process of growth. The proximal epiphysial cartilage of the tibia

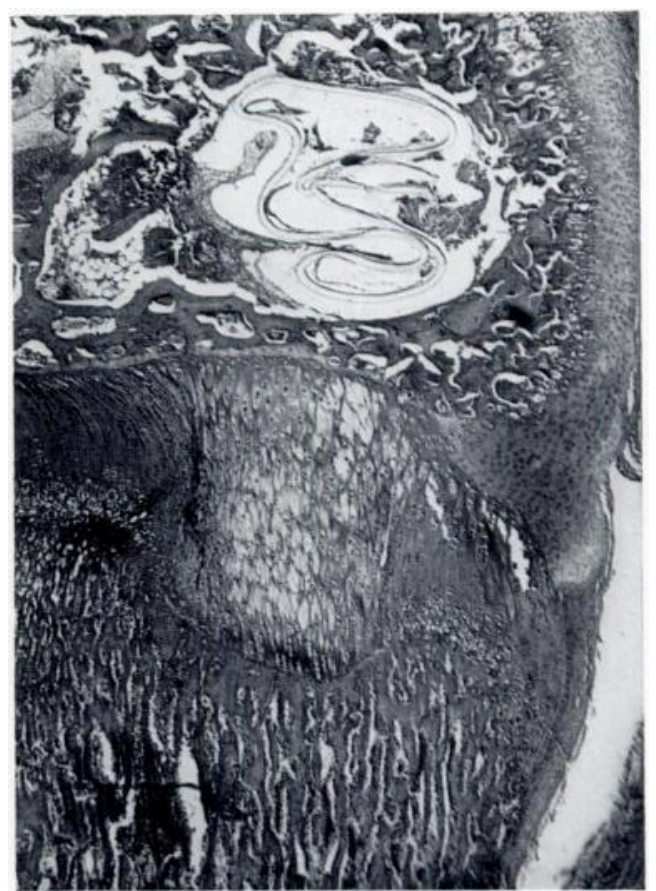

FIG. 7

After interruption of the epiphysial blood supply to an area of the growth cartilage the chondrocytes immediately underneath die and the columnar arrangement becomes disorganised. Rabbit. ( $\times 30$.)

vOL. 45 B, NO. 2, MAY 1963 
was investigated under " normal " (unaltered) conditions and after experimental interference. This work is now in the course of publication. The vascular arrangements at each side of the epiphysial cartilage have been shown to fulfil two totally different functions (Trueta and Morgan 1960). The epiphysial vessels nourish the proliferative, proximal ends of the cell columns, whereas the metaphysial vessels are responsible for the removal by vascular invasion of the hypertrophic cartilage cells which precedes ossification. It was also found that the two systems of vessels anastomose with each other by perichondral vascular branches (Morgan 1959): thus an increase of the epiphysial circulation, as in severe synovitis, will also cause some increase of the metaphysial blood flow which will help in preventing the lengthening of the cell column instead of the accelerated growth of the particular bone.

We have seen that the experimental suppression of the epiphysial blood flow, if either persistent or extensive, will cause severe damage to the growth cartilage (Fig. 7). Conversely, the experimental discontinuation of the metaphysial blood flow preserves the growth cartilage

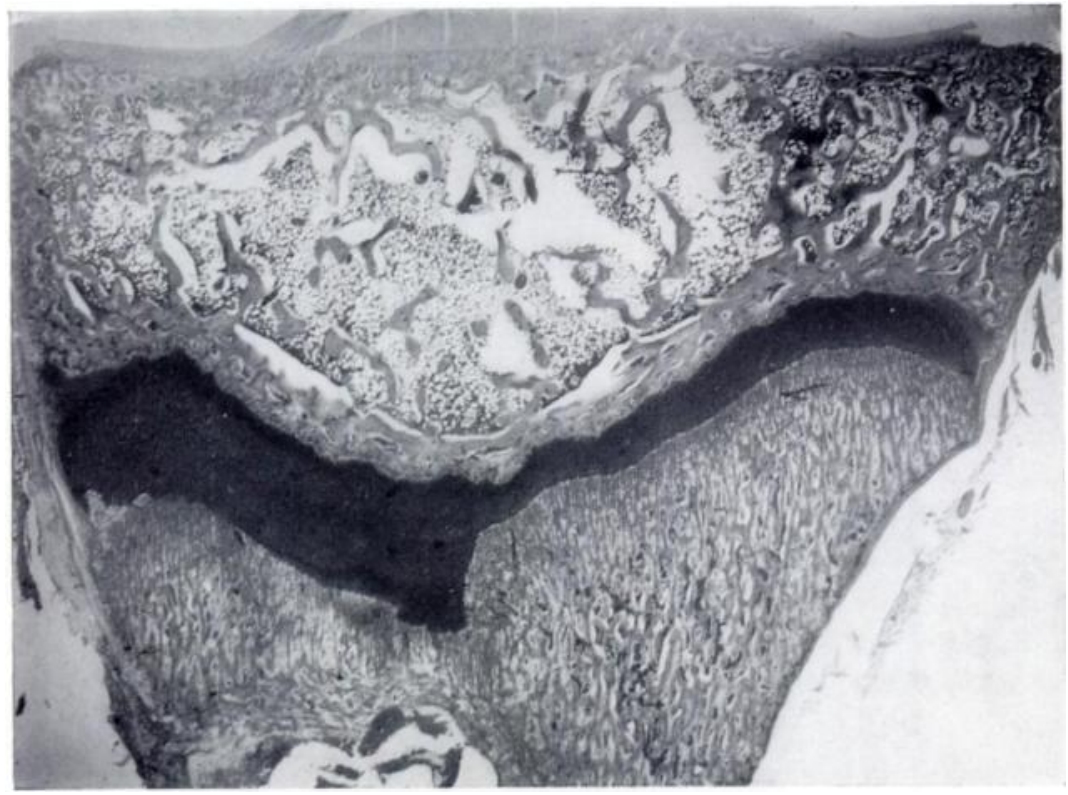

FIG. 8

The experimental suppression of blood flow to the metaphysial side of the growth cartilage (left of picture) preserves its cells while new ones are added at the epiphysial side. This results in a three-fold or four-fold increase of the height of the epiphysial cartilage as in rickets. $(\times 20$.

in a manner reminiscent of rickets (Trueta and Amato 1960) (Fig. 8). The essential difference between the two systems of vessels lies in the inability of the epiphysial vessels to penetrate the cell columns, whereas the vascular loops of the metaphysial side spring forward as soon as the proper degree of degeneration has overtaken the hypertrophic cells at the end of the columns. This peculiar behaviour of the metaphysial vessels adjacent to the growth cartilage is reminiscent of that which had already been seen to occur in osteoarthritis (Harrison et al. 1953). There, too, the usual inability of the vascular loops to penetrate the thin calcified layer of the joint cartilage is overcome and vessels sprout, invading the degenerating joint cartilage in the areas where the amount of joint pressure would permit such a proliferation. We believe that the vascular stimulating factor must have been produced in both cases, growth or osteoarthritis, by the mediation of the degenerating cartilage cells.

Further confirmation of these findings was obtained in the work on the vascularity of the callus of fracture already mentioned (Trueta and Cavadias 1955, Cavadias 1958). In all 
the rabbits perfused during the process of healing after fracture it was found that the vessels from the soft tissue surrounding the fracture site, including the stripped periosteum, progressed not towards the nearest underlying cortex but towards the area of devitalised bone at the end of the fragments and the adjacent zone occupied by the hypertrophic cartilage cells (Trueta 1961a), similar to those of the hypertrophic segment of the growth cartilage. This systematic direction of the vessels gave a radiating appearance to the vascular pattern of the callus and pointed clearly to the existence of the vascular stimulating factor in or near the fracture line (Fig. 9).

If more support for these views were necessary, the varying vascular reactions to bone grafting to which we have referred before may also be adduced. The specific stimulus of bone grafting on osteogenesis depends, we believe, on the decay and final death of the osteocytes and endothelial cells (or of nearly all of them), and the appeal this causes to the vessels of the host tissue by the production of the vascular stimulating factor. After the initial stimulus an antibody reaction felt by the vessels may be added, depending on the nature of the bone graft (Heslop, Zeiss and Nisbet 1960; Trueta 1960). The activity of the vascular stimulating factor is even felt at a

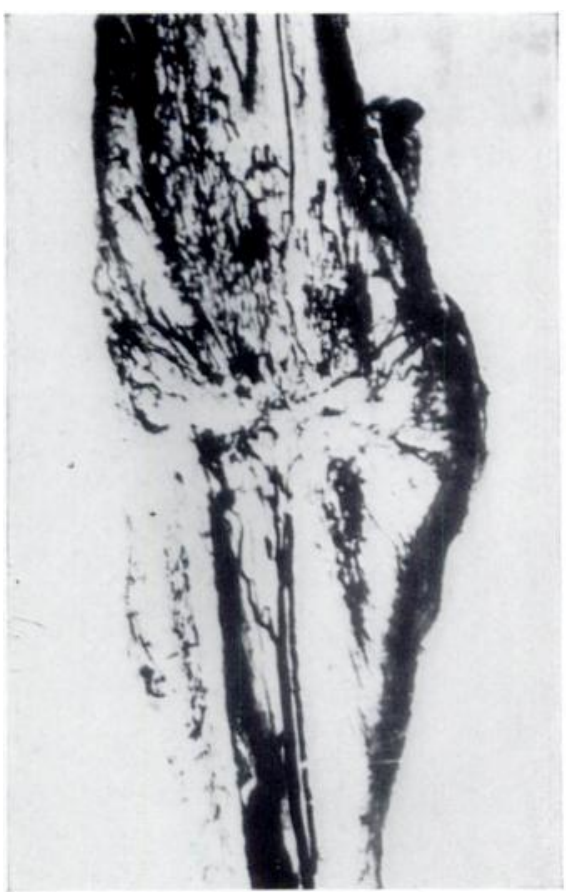

FIG. 9

Experimental fracture of the radius in a rabbit. The perfused vessels all point towards the ischaemic ends of the bone fragments and the mature cartilage. The vascular stimulating factor (V.S.F.) is produced there. $(\ltimes 8$. certain distance from the graft as shown in the Phemister method of grafting, in which the bone grafts producing the factor are unattached to the bone in which osteogenesis is being stimulated. Inveterate non-union of bone often consolidates after a new vascular invasion of the old fibrous tissue which had kept the bone fragments apart.

Up to now we have reported findings favouring the view that a direct vascular invasion precedes ossification but we have not yet explained the way by which these vessels are responsible for the genesis of bone. This brings us to the study of the osteogenetic vessel, perhaps the most substantial and significant, even if also the most controversial, contribution that has come out of the various investigations reported here.

\section{BONE CAPILLARIES AND SINUSOIDS}

In 1900 Minot described in the liver, heart, suprarenal capsules, parathyroid glands and other tissues the peculiar vessels he named sinusoids. These vessels differ from ordinary capillaries in their large size and irregular shape and in their endothelium, closely applied over the epithelial cells of the organ. While the capillary appears totally surrounded by " connective tissue" cells, the sinusoid is poorly provided with such cells interposed between itself and the cells of the organ.

This original description by Minot has found ample confirmation, most recently by Policard and Collet (1961), but it must be remembered that in his initial work Minot failed to include the bones among the organs he studied. Subsequent works by Minot (1912), Doan (1922), Doan, Cunningham and Sabin (1925) and Drinker, Drinker and Lund (1922) filled this gap, but we could not find any photographic or radiographic representation of the bone sinusoids in the human at the time we published our first paper on the subject (Trueta and Harrison 1953). Protracted discussions on the origin of the endothelium and on its 
function have for long appeared in the medical journals: for this reason it is our purpose here to refer only to a few fundamental works of which the importance has not been sufficiently recognised. That no easy explanation would be found of the nature and function of the endothelium was foreseen by Doan (1922), who after his meticulous study of the sinusoids of adult pigeons, dogs, cats, rabbits and rats concluded that the immediate question was of the function of the vast bed for endothelium extending through the bone marrow.

Sabin (1920) in her classic work on the embryology of the chick demonstrated that an extensive differentiation of angioblasts takes place out of the area pellucida at the second day of incubation and that this decreases from the third day onwards. The division of the angioblasts forms syncytial masses which liquefy in the centre, and the cells lining the new cavities differentiate about the seventh incubation day into endothelial cells. From then on

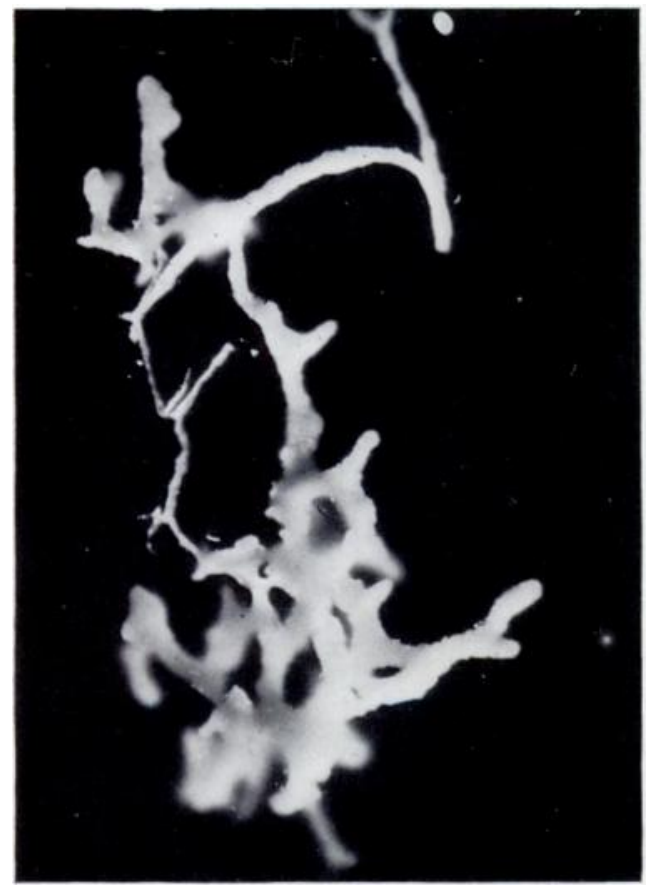

Fig. 10

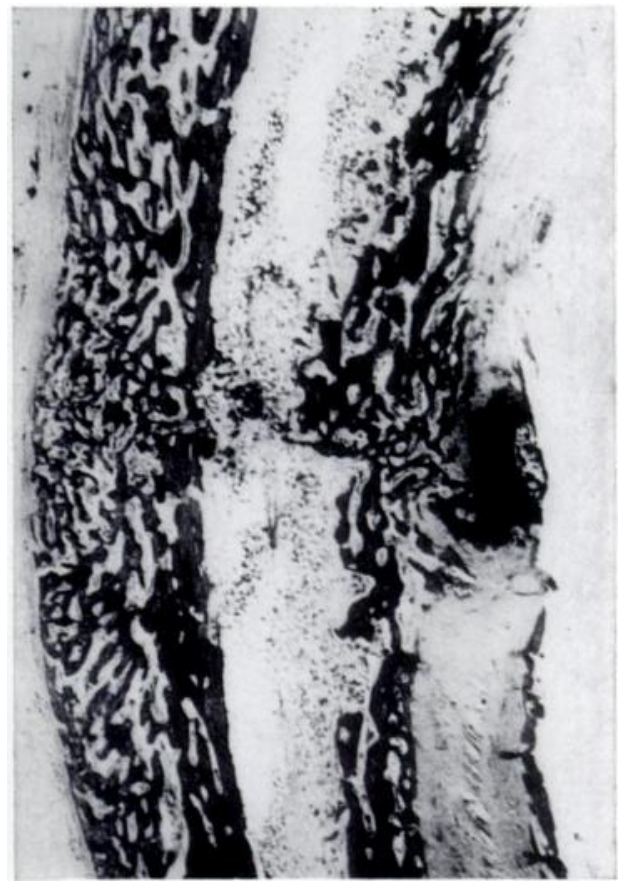

Fig. 11

Figure 10-Sinusoid of a human bone perfused with latex and corrosion. Note the arteriole at the top end of the sinusoid. $(\times 17$. $)$ Figure 11-Radiating orientation of provisional trabeculae in the callus of an experimental fracture in the rabbit. These trabeculae are exactly moulded on to the vascular pattern $(\times 10$.

the progress of the vessels is made by division of the endothelial cells, a division which accompanies vascular sprouting. Under the influence of unknown stimuli (our V.S.F.) the endothelium returns to its embryonic angioblastic condition as occurs in wound repair (Holman 1920). Sandblom (1944) saw that the fibroblasts and the endothelial cells were responsible for healing, and Robertson (1945) observed that fibrocytes came from the capillary wall and from the histiocytes round the wound area. In his recent extensive study of wound repair Allgöwer (1956) re-established facts postulated long ago by Maximow (1902). He concluded that endothelial cells and the perivascularly located blood cell participate in mitosis but that the latter forms the chief source of new, regenerated, young connective tissue. What we wish to stress here is the relationship between the intraosseous cells and osteogenesis. A further word may be necessary to explain why we purposely use the term vessels instead of the more descriptive one of capillary or sinusoid. Lewis (1927) confronted with the same difficulty named them "minute vessels." The reason is that in bone a border-line between 
the two does not exist, most of the fine arterioles ending in single-walled vessels which may or may not be taken as belonging to the capillary system according to the original conception of Malpighi (Fig. 10). What appears certain is that, depending on local or general requirements such as active haemopoiesis or osteogenesis, sinusoids may become distended or may shrink and be invisible. Doan (1922) claimed that the venous sinusoids form the principal functioning vascular bed for the circulating blood in the bone marrow, which corresponds to the capillaries of other organs, and this assertion still holds true. By starvation experiments he was able to

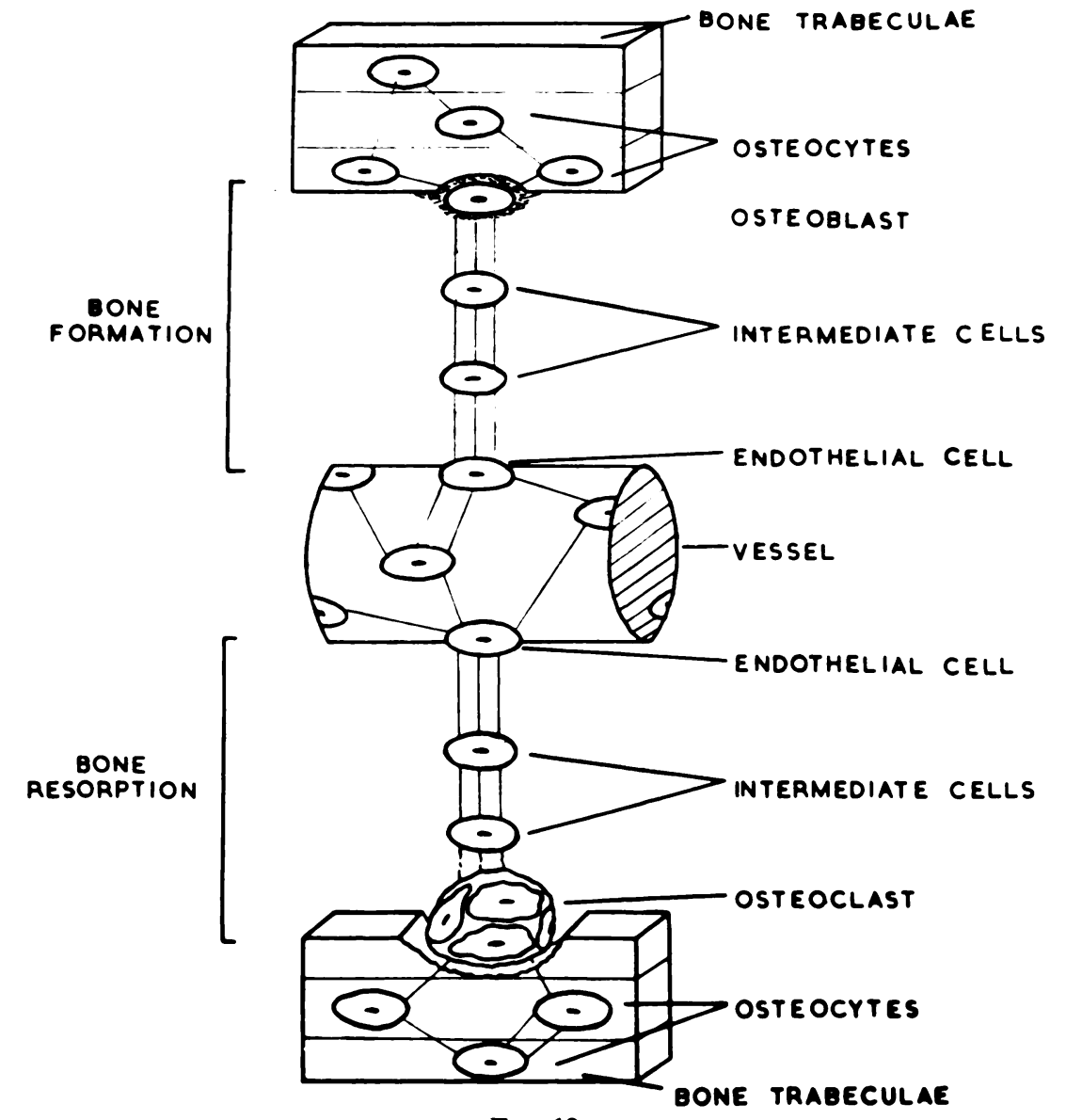

Fig. 12

Schematic representation of the progeny of the bone cell and osteoclast. From the vascular endothelium to the osteoclast an uninterrupted syncytium maintains the connection between the osteocyte and the adjacent vessel responsible for its nourishment. Changes in this vessel or in the blood it carries are responsible for the alternating process of bone formation (upper part of the diagram) or for bone removal (lower part of diagram).

demonstrate in the hypoplastic bone marrow of the pigeon an extensive system of unsuspected capillaries. In our work on this subject (Trueta and Harrison 1953) we concluded that any extension of the haemopoietic tissues in bone is accompanied by the conversion of the capillaries into sinusoids, and we have found no evidence to suggest that this assertion was wrong.

In the course of the last ten years of research on the vascularity of bone what has appeared more and more evident to us is that the fine vasculature of bone, comprising under appropriate circumstances both capillaries and sinusoids, is responsible for the deposition of bone. It is furthermore likely that under other conditions the vessel is also the main agent of bone removal. 
The evidence in support of the osteogenetic properties of the bone vessels has been accumulated during investigations into the vasculature of the callus of fractures and of the growth cartilage, into the incorporation of bone grafts, and into osteoporosis following muscle inactivity. We have concluded that the factors underlying the unexplained Wolff laws of trabecular deposition and orientation (1870) are mediated by the particular positioning of the osteogenetic vessels (Trueta 1956b, 1958, 1960, 1961a).

The osteogenetic activity of the cells of the vascular wall has been studied in the callus of fractures. As reported before, the progression of the vessels is towards the ischaemic area at the centre of the fracture site. But what seems relevant here is that the deposition of new bone in the form of provisional trabeculae is also found in radiating form, exactly moulded on to the vascular pattern (Fig. 11).

The following is a summary of the way in which we believe the vessels enter into osteogenetic activity. The endothelial cells of the walls of the advancing vessels divide not only at their extending ends but along large sections of their wall and lay down a progeny of either osteoblasts or their near predecessors (Trueta 1961b). All these cells, from endothelium to osteocyte, remain attached by intercellular cytoplasmic connections. After the osteoblasts have laid down the collagen and polysaccharide matrix and have subsequently become buried by the deposition of apatite, the cytoplasmic attachments to their ancestors prevent the deposit of mineral from forming an isolating wall. Canaliculi will thus appear round each of the cell expansions and the original syncytium will be preserved by the rigid mineral structure characteristic of bone (Fig. 12).

We have studied with the help of the electron microscope the successive stages by which these vascular cells become incorporated into bone, and with the collaboration of $\mathrm{Dr} \mathrm{K}$. Little we have been able to illustrate this point to our satisfaction. The reason why we have been able to collect all this evidence on the vessel wall is because our sections, including most of those for the electron microscope, have been obtained from perfused specimens in which the vascular lumen remains patent (Trueta and Little 1960). The information that we have obtained relating to the area of active bone formation in the calcified tubes of the metaphysis during growth is abundant, and Rigal (1961a) in our laboratories has found by cell labelling with tritiated thymidine that many of the endothelial cells of the vessel wall enter the synthetic phase of their mitotic cycle: that is to say they are preparing to divide.

\section{EFFECT OF COMPRESSION ON OSTEOGENESIS}

Experimental evidence on the osteogenetic activity of the bone vessels has been obtained from rabbits, the epiphyses of which had been subjected to persistent heavy compression by the use of a specially designed clamp (Trias 1961). Excessive compression awakened the osteogenetic activity of the vascular wall and caused an increase in bone deposition in the compressed area, with concomitant reduction of the vascular lumen after each new ring of osteoblasts had become incorporated into the new bone as osteocytes. A stage was finally reached when large areas of bone were deprived of circulating blood and "bone sclerosis" occurred, with alternation of dead and living bone. In these cases the death of the osteocytes was being caused by the final obliteration of the central blood vessel from which they received their nourishment (Fig. 13). Harrison et al. (1953) showed that in osteoarthritis of the hip in humans the areas of increased bone density were close to the areas that were more vascular. This we believe to be the mechanism of bone sclerosis. It may explain why increasing bone density has been considered by radiologists and clinicians to be synonymous with dead bone. Further indirect evidence on the vascular nature of the bone deposition in bone sclerosis may be found in the work of Cram in the dog (1955) and that of Bobechko and Harris in the rabbit (1960). We thus consider enhanced osteogenetic vascularity to be responsible for the 
accelerated bone union that occurs when compression is applied after osteotomy, joint resection and fractures, as recommended by Key (1932) and Charnley (1948).

Moreover, we see in the reduction of lumen of the bone canaliculi the main stimulus to trabecular deposition which the so-called Wolff laws have failed to explain. Under repeated persistent compression in any particular direction, such as that caused by weight bearing or muscle contraction, the canaliculi running in a direction more or less perpendicular to the compressing force become closed. Cut off from the transudates supplied by the nearby parent

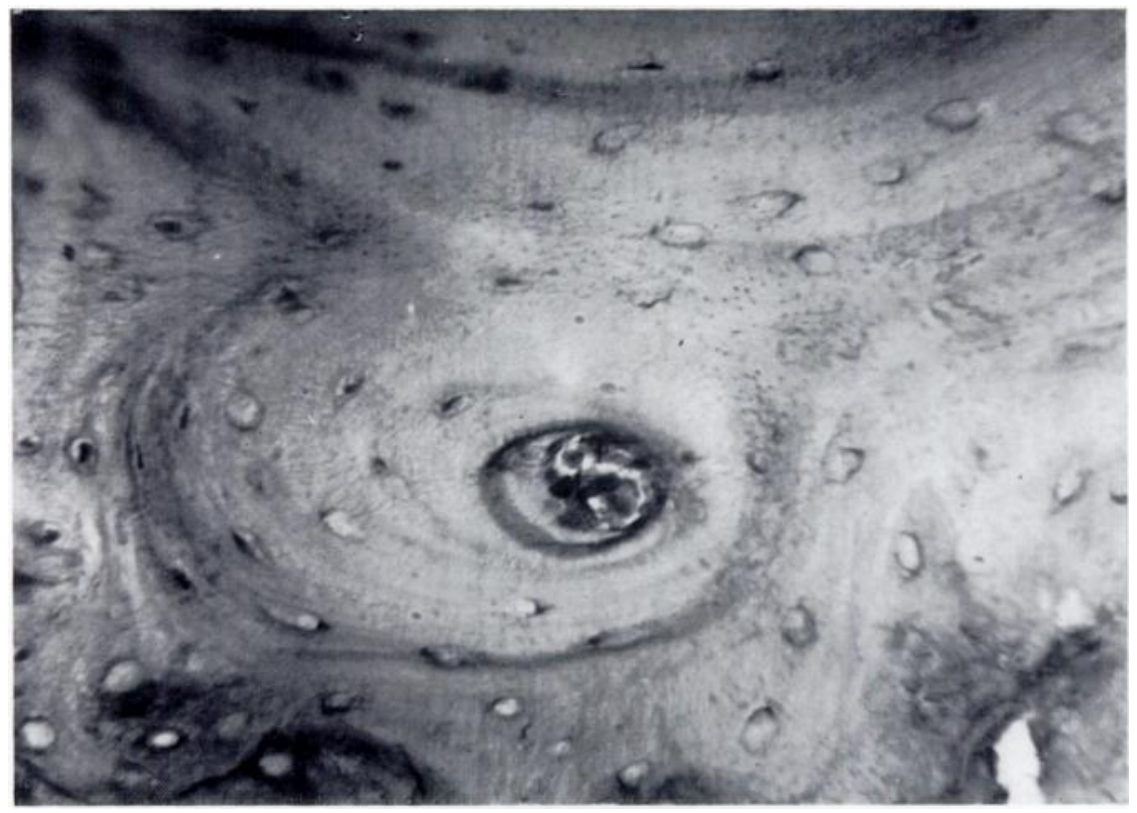

Fig. 13

A central vessel after excessive bone deposition has caused its lumen to be insufficient for the blood flow required to keep so many concentric layers of osteocytes alive. Bone sclerosis and bone death are thus consecutive to unrestricted, active bone formation. $(\because 250$.)

vessel the osteocytes and other intra-osseous cells suffer and, in extreme cases, even die. The vascular stimulating factor is thus produced and under its influence newly formed vessels move along the compressed trabeculae and subsequently give origin to the osteoblasts, as we have mentioned when referring to bone formation in the callus of fractures.

\section{THE VASCULAR ORIGIN OF THE HAVERSIAN SYSTEM AND OSTEONES}

It may be asked whether this concept of bone formation is valid when applied to the origin of the Haversian system of the osteones. Consequently it was thought necessary to explain the role that the vessels play in the organisation of the Haversian systems of cortical bone.

The facts presented here were obtained by the use of the electron microscope and particularly by microscopy under ultra-violet light after the injection of tetracycline and the subsequent perfusion of the animal-usually the guinea-pig or rat-with a 2 per cent solution of Berlin blue.

The part that the periosteal vessels play in nourishing the outer layers of the cortex has been mentioned before. We must now point out that the vascularity of the periosteum is much greater during growth than after it has stopped. But in both young and adult animals 


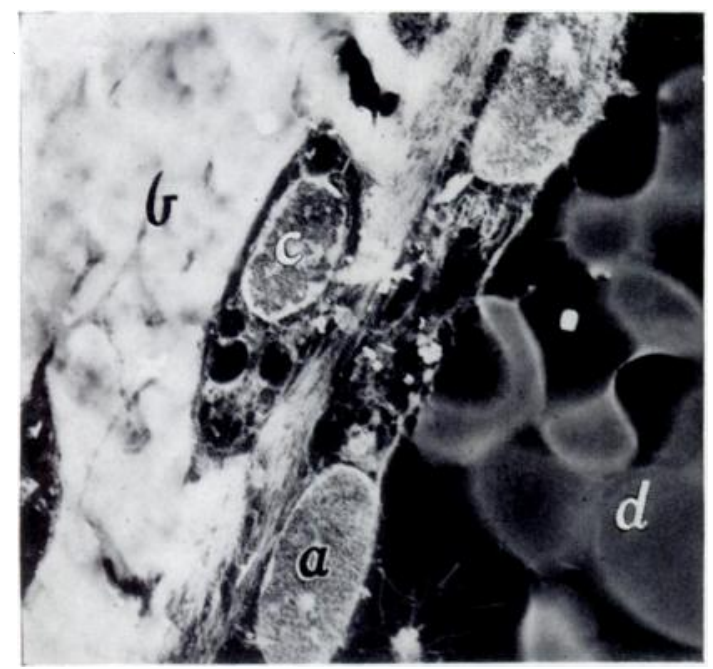

FIG. 14

Vessel wall in direct connection with active osteoblast in the process of becoming incorporated into bone. The crescent-shaped figures at the right side of the picture are intravascular red corpuscles. $a=$ endothelial cell; $b=$ bone; $c=$ osteocyte; $d=$ erythrocyte.

$$
\text { microscope photograph, } \times 3,500 \text {.) }
$$

the vessels of the periosteum appear as much responsible for the origin of the osteoblasts as are those of the trabecular system, or more so.

The deposition of subperiosteal bone is made in successive layers, each of which is vascular in origin. On close examination of the single or double vessel of the Haversian canal after perfusion it often appears that the endothelial cell is in immediate contact with the osteoblasts, either directly or separated by a single cell (Fig. 14). With ultra-violet microscopy the tetracycline deposition, which indicates the area of previous labour of the osteoblasts, so perfectly corresponds with the outer perimeter of the vessel that the only rational conclusion seems to be that both of them are intimately related.

In the light of these findings one cannot but admire the perfect arrangement by which the transudates from the central vessel can reach the cells at the depth of the osteone.

Each row of osteocytes keeps its syncytial link by means of its cytoplasmic prolongation with the row it encircles until the more central line of osteocytes embraces and connects the osteoblasts and these the cells of the vascular wall (Fig. 15). This material is now being prepared for publication in collaboration with Dr Rios Leal.

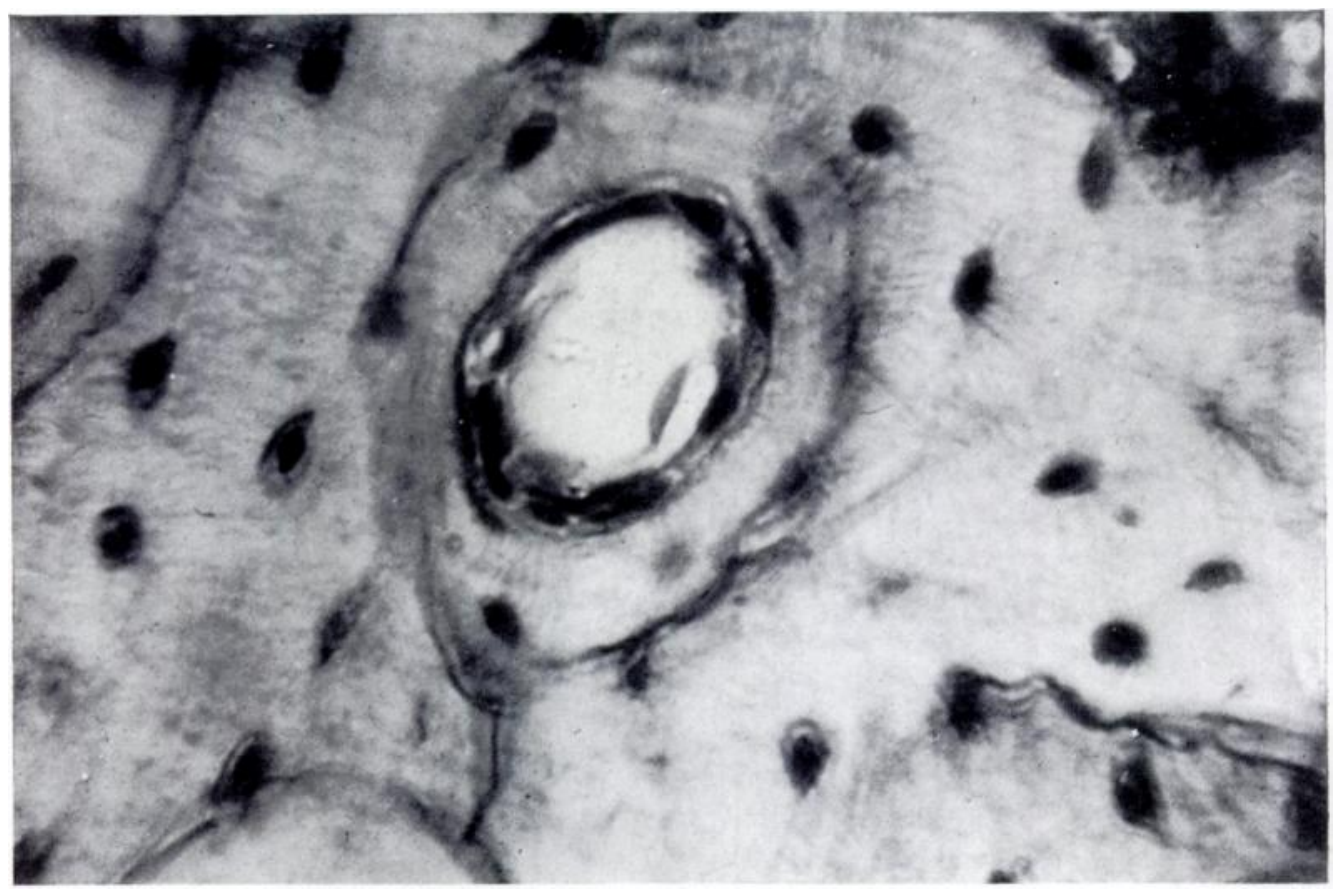

FIG. 15

Haversian canal in its final phase before resorption begins. The row of osteoblasts is closely connected with the cells of the constricted vessel wall. (Photomicrograph, $\times 525$.) 
BONE REMOVAL AND THE OSTEOCLASTS

We have already referred to the mechanism of bone removal and have pointed out that the normal process of bone resorption depends on vascular changes, either local or systemic. It is already well known that either reduced apposition of bone or its increased resorption can be produced by withdrawing from the blood some of the essentials required for bone formation, such as oxygen, vitamins $\mathrm{A}, \mathrm{C}$ and $\mathrm{D}$, and calcium and phosphate salts. We shall now discuss in the light of some of our findings the possible role of the osteoclasts as the agents of bone removal.

We have been able to obtain photomicrographs of osteocytes connected to neighbouring osteoclasts by cytoplasmic expansions of exactly the same nature as those linking osteocytes with each other or with the osteoblasts in their vicinity (Trueta 1958). No other explanation was found except that the osteoclasts include osteocytes and probably nearby osteoblasts from the same area of the syncytium. Young (1962) has shown that tritiated thymidine is taken up by the osteoblasts and osteocytes but not by the osteoclasts, despite which some contain labelled nuclei. Thus they must be formed by fusion of other cells, presumably intermediate cells, osteoblasts and osteocytes. In this he coincides in general with Tonna (1960). This evidence further supports the view that the osteoclasts are formed by osteocytes, osteoblasts or the intermediate cells. Rigal $(1961 b)$ has also found evidence of this in his labelled material.

In bone resorption caused by muscle inhibition (Geiser and Trueta 1958) the osteoclasts were abundant. This proves no more than that in this type of osteoporosis osteoclasts are formed in large numbers. But are they the initiators of bone removal, as Kölliker (1873) thought they were, or are the osteoclasts a simple consequence of the resorption of bone, as Recklinghausen (1891) believed? This is not an academic question because if it were possible to clear up this point the control of such a severe disability as clinical osteoporosis would be nearer.

We have little doubt about this. Dozens of works and papers on the origin of the osteoclasts by authors who assign a specific nature to such cells have failed to discover where they come from and why they appear. Again no light has been thrown on the final destination of the bone cells and their syncytial connections, which must be left to withstand conditions for which they were not prepared, once the crystals of apatite have been washed away in the early stages of bone removal. We believe, like Arey (1919) and others, that the osteocytes and osteoblasts deprived of the rigid structure which keeps them in stable position can coalesce to form the multinucleated cells Kölliker christened osteoclasts. In one point we may differ from the workers who doubted the aggressive nature of the osteoclasts and denied any osteolytic power to them. It has been widely recognised that degenerating or dead osteocytes liberate some substance that is responsible for the removal of the mineral limiting the bone lacunae. It may well be that the accumulation of defected osteocytes preserves in the osteoclast, even perhaps enhances, the aggressive property of the osteocytes from which they are mainly formed. But this does not deter us from believing that what causes the osteoclast to appear is the initial bone removal caused by the vascular mechanism to which we have referred. Kelly, Little and Courts (1959) have shown the part that an alteration of the matrix plays in causing osteoporosis.

\section{CONCLUSIONS}

We have attempted to summarise in a short space investigations that have occupied several years, and we realise that whatever the merits of such an effort the results can only be modest. Many important aspects of the osteogenetic process still remain a mystery and thus are subjected to theory and controversy. Such is the case with this constant attendant at osteogenesis which is alkaline phosphatase. But of one thing we are certain, namely that bone is an organised " soft" tissue of which only part has been made rigid by the deposit of calcium salts. The organiser is the osteogenetic vessel from which springs the syncytial frame of cells and their connections on which the bone architecture is established. Endothelial cell,

voL. 45 B, NO. 2, MAY 1963 
intermediate cell, osteoblast, osteocyte, osteoclast; these constitute the normal sequence of cellular phylogeny in the constant elaboration and removal of the bone substance. The initial cells on which the whole process rests are those of the capillary-sinusoid vessel which is responsible for providing the transudates on which the life and health of the whole syncytium depends.

If our findings were confirmed, a better understanding of the nature and characteristics of primitive malignant bone tumours would be possible. Each type of tumour from endothelioma to malignant osteoclastoma, including reticulum-cell sarcoma and osteogenic sarcoma, would be initiated by a different cell of the syncytium, but in its monstrous deviation from the normal would still preserve most of the characteristics of its healthy ancestor. Thus the endothelioma causes bone expansion, bone reaction and even bone necrosis, but not proper bone formation, whereas the osteogenic sarcoma or osteoblastoma forms bone; and with the same fidelity to their origin osteoclasts are seen in the malignant osteolytic tumour.

Over thirty years ago the late Sir Arthur Keith (1927) expressed his suspicion that the cells which assume a bone-forming role are derived from the endothelium of the capillary system. We hope we have contributed to show that his suspicion was right.

\section{REFERENCES}

Allgöwer, M. (1956): The Cellular Basis of Wound Repair. Springfield, Illinois: Charles C. Thomas.

ANNersten, S. (1940): Experimentelle Untersuchungen über die Osteogenese und die Biochemie des Fracturcallus. Acta Chirurgica Scandinavica, 84, Supplementum 60.

AREY, L. B. (1919): The Origin, Growth and Fate of Osteoclasts and their Relation to Bone Resorption. American Journal of Anatomy, 26, 315.

Barclay, A. E. (1951): Micro-arteriography. Oxford: Blackwell Scientific Publications.

Barnes, J. M., and Trueta, J. (1941): Absorption of Bacteria, Toxins and Snake Venoms from the Tissues. Lancet, i, 623.

Barnes, J. M., and Trueta, J. (1942): Arterial Spasm. British Journal of Surgery, 30, 74.

Bernard, C. (1855-56): Leçons de physiologie expérimentale appliquée à la médecine. Paris: J. B. Baillière.

Blair, H. C. (1938): The Alternation of Blood Supply as a Cause for Normal Calcification of Bone. Surgery, Gynecology and Obstetrics, 67, 413.

Bobechкo, W. P., and Harris, W. R. (1960): The Radiographic Density of Avascular Bone. Journal of Bone and Joint Surgery, 42-B, 626.

Bridges, J. B., and Pritchard, J. J. (1958): Bone and Cartilage Induction in the Rabbit. Journal of Anatomy, 92, 28.

Brodetri, A. (1960): The Blood Supply of the Femoral Neck and Head in Relation to the Damaging Effects of Nails and Screws. Journal of Bone and Joint Surgery, 42-B, 794.

Brookes, M., Elkin, A. C., Harrison, R. G., and Heald, C. B. (1961): A New Concept of Capillary Circulation in Bone Cortex. Lancet, $\mathrm{i}, 1,078$.

Cavadias, A. X. (1958): Studies on the Vascular Participation in the Formation of the Callus of Fractures (in Greek). Athens: M.D. Thesis.

Charnley, J. C. (1948): Positive Pressure in Arthrodesis of the Knee Joint. Journal of Bone and Joint Surgery, 30-B, 478.

Claffey, T. J. (1960): Avascular Necrosis of the Femoral Head. Journal of Bone and Joint Surgery, 42-B, 802.

Cram, R. H. (1955): Personal communication.

Deleu, J. (1962): Personal communication.

Doan, C. A. (1922): The Circulation of the Bone-Marrow. Contributions to Embryology, 14, 27.

Doan. C. A., Cunningham, R. S., and Sabin, F. R. (1925): Experimental Studies on the Origin and Maturation of Avian and Mammalian Red Blood-Cells. Contributions to Embryology, 16, 163.

Drinker, C. K., Drinker, K. R., and Lund, C. C. (1922): The Circulation in the Mammalian Bone-Marrow. American Journal of Physiology, 62, 1.

Drinker, C. K., and FIELD, M. E. (1933): Lymphatics, Lymph and Tissue Fluid. London: Baillière, Tindall $\&$ Cox.

Duhamel, H. L. (1742): Sur le développement et la crue des os des animeaux. Histoire et Mémoires de l'Académie des Inscriptions et Belles Lettres, 2, 481.

Esteve, R. (1957): A Study of Muscle Paralysis, Autonomic Disorders and Nutritional Disturbances in Poliomyelitis. Oxford: D.Phil. Thesis. 
Flourens, J. P. M. (1842): Recherches sur le développement des os et des dents. Paris: Gide.

Foster, L. N., Kelly, R. P., Jun., and WAtTS, W. M., Jun. (1951): Experimental Infarction of Bone and Bone Marrow. Journal of Bone and Joint Surgery, 33-A, 396.

Franklin, K. J. (1937): A Monograph on Veins. Springfield, Illinois: Charles C. Thomas.

Gegenbaur, C. (1864): Ueber die Bildung des Knochengewebes. Jenaische Zeitschrift für Naturwissenschaft, $1,343$.

Geiser, M., and Trueta, J. (1958): Muscle Action, Bone Rarefaction and Bone Formation. Journal of Bone and Joint Surgery, 40-B, 282.

GinsBurg, J. (1958): Observations on the Peripheral Circulation in Hypertrophic Pulmonary Osteoarthropathy. Quarterly Journal of Medicine, N.S. 27, 335.

Goodsir, J., and GoodsIR, H. D. S. (1845): Anatomical and Pathological Observations. Edinburgh: M. Macphail.

Haller, A. (1763): Experimentorum de ossium formatione. In Opera minora, vol. 2, p. 400 . Lausanne: Francisci Grasset.

Harrison, M. H. M., Schajowicz, F., and Trueta, J. (1953): Osteoarthritis of the Hip: A Study of the Nature and Evolution of the Disease. Journal of Bone and Joint Surgery, 35-B, 598.

Henderson, Y., Oughterson, A. W., Greenberg, L. A., and Searle, C. P. (1934): The Third Major Mechanical Factor in the Circulation of the Blood. Science, 79, 508.

Heslop, B. F., Zeiss, I. M., and Nisbet, N. W. (1960): Studies on Transference of Bone. British Journal of Experimental Pathology, 41, 269.

Holman, E. (1920): End-to-end Anastomosis of the Intestine by Presection Sutures. Johns Hopkins Hospital Bulletin, 31, 300.

Hunter, J. (1835): Works. Vol. 1, p. 502. London: Longman, Rees, Orme, Brown, Green, and Longman.

JoNes, F. Wood (1917): The Relation of Structure to Function as Seen in a Mechanism of the Venous System. Lancet, i, 574.

KeIth, Sir A. (1927): Concerning the Origin and Nature of Osteoblasts. Proceedings of the Roval Society of Medicine (Section of Surgery), 21, 301.

Kelly, M., Little, K., and Courts, A. (1959): Bone Matrix and Osteoporosis. Lancet, ii, 1,125.

Key, J. A. (1932): Positive Pressure in Arthrodesis for Tuberculosis of the Knee Joint. Southern Medical Journal, 25, 909.

Kölliker, A. (1873): Die normale Resorption des Knochengewebes. Leipzig: F. C. W. Vogel.

LACroIX, P. (1951): The Organization of Bones. London: J. \& A. Churchill Ltd.

Leriche, R., and PolicARD, A. (1926): Les problèmes de la physiologie normale et pathologique de l'os. Paris: Masson \& Cie.

LeVANDER, G. (1938): A Study of Bone Regeneration. Surgery, Gynecology and Obstetrics, 67, 705.

LewIS, Sir T. (1927): The Blood Vessels of the Human Skin and their Responses. London: Shaw \& Sons Ltd.

LiMA, C. (1961): Personal communication.

MACEWEN, Sir W. (1912): The Growth of Bone. Observations on Osteogenesis. Glasgow: J. Maclehose \& Sons.

Macnab, I. (1958): The Blood Supply of Tubular and Cancellous Bone. Journal of Bone and Joint Surgery, 40-A, 1,433 .

Maximow, A. (1902): Experimentelle Untersuchungen über die entzündliche Neubildung von Bindegewebe. Jena: G. Fischer.

Mendlowitz, M., and Leslie, A. (1942): The Experimental Simulation in the Dog of the Cyanosis and Hypertrophic Osteoarthropathy which are Associated with Congenital Heart Disease. American Heart Journal, 24, 141.

Minor, C. S. (1900): On a Hitherto Unrecognised Form of Blood Circulation without Capillaries in the Organs of Vertebrates. Proceedings of the Boston Society of Natural History, 29, 185.

Minot, C. S. (1912): Development of the Blood. In Manual of Human Embryology. Edited by F. Keibel and F. P. Mall, Vol. 2. Philadelphia and London: J. B. Lippincott Company.

Morgan, J. D. (1959): Blood Supply of Growing Rabbit's Tibia. Journal of Bone and Joint Surgery, 41-B, 185.

Ollier, L. (1867): Traité expérimental et clinique de la régénération des os et de la production artificielle du tissu osseux. Paris: V. Masson et fils.

Policard, A., and Collet, A. (1961): Physiologie du tissu conjonctif normal et pathologique. Paris: Masson \& Cie.

Recklinghausen, F. von (1891): Die fibrose oder deformirende Ostitis, die Osteomalacie und die osteoplastische Carcinose in ihren gegenseitigen Beziehungen, In Festschrift Rudolf Virchow. Berlin: Georg Reimer.

Rigal, W. M. (1961a): A Study of Bone Development using Tissue Culture as the Main Technique. Oxford: D.Phil. Thesis.

Rigal, W. M. (1961b): Personal communication.

Robertson, F. O. (1945): Pathological Histology. Edinburgh: E. \& S. Livingstone.

SABIN, F. R. (1920): Studies on the Origin of Blood-Vessels and of Red Blood-Corpuscles as Seen in the Living Blastoderm of Chicks During the Second Day of Incubation. Contributions to Embryology, 9, 213.

VOL. 45 B, NO. 2, MAY 1963 
Sandblom, P. (1944): The Tensile Strength of Healing Wounds. Acta Chirurgica Scandinavica, 90, Supplementum 89.

Stringa, G. (1957): Studies of the Vascularisation of Bone Grafts. Journal of Bone and Joint Surgery, 39-B, 395.

Syme, J. (1840): On the Power of the Periosteum to Form New Bone. Transactions of the Royal Society of Edinburgh, 14, 158.

TonnA, E. A. (1960): Osteoclasts and the Aging Skeleton: a Cytological, Cytochemical and Autoradiographic Study. Anatomical Record, 137, 251.

Trias, A. (1961): Effect of Persistent Pressure on the Articular Cartilage. Journal of Bone and Joint Surgery, 43-B, 376

TruetA, J. (1953): Acute Haematogenous Osteomyelitis: its Pathology and Treatment. Bulletin of the Hospital for Joint Diseases, 14, 5.

TruetA, J. (1956a): Le mécanisme vasculaire de l'ostéoporose. Etude physiopathologique et expérimentale. Acta Chirurgica Belgica et Acta Orthopaedica Belgica, Supplement 1, 165.

Trueta, J. (1956b): Osteo-Arthritis. Lancet, i, 585.

Trueta, J. (1957): The Normal Vascular Anatomy of the Human Femoral Head during Growth. Journal of Bone and Joint Surgery, 39-B, 358.

Trueta, J. (1958): La vascularisation des os et l'ostéogénèse. Revue de Chirurgie Orthopédique, 44, 3.

Trueta, J. (1959): The Three Types of Acute Haematogenous Osteomyelitis. Journal of Bone and Joint Surgery, 41-B, 671.

Trueta, J. (1960): Bone Grafting. Nursing Mirror, 20 May, 110, 5.

TRUETA, J. (1961a): Etudes sur l'ostéogenèse réparatrice avec un nouveau concept sur l'origine de l'os. Lille Medical, 3e Série, 6, 1,031 .

Trueta, J. (1961b): The Housing Problem of the Osteoblast. Journal of Trauma, 1, 5.

Trueta, J., and Amato, V. P. (1960): The Vascular Contribution to Osteogenesis. III. Changes in the Growth Cartilage Caused by Experimentally Induced Ischaemia. Journal of Bone and Joint Surgery, 42-B, 571.

Trueta, J., Barclay, A. E., Daniel, P. M., Franklin, K. J., and Prichard, M. M. L. (1947): Studies of the Renal Circulation. Oxford: Blackwell Scientific Publications.

Trueta, J., and Cavadias, A. X. (1955): Vascular Changes Caused by the Küntscher Type of Nailing. Journal of Bone and Joint Surgery, 37-B, 492.

Trueta, J., and Harrison, M. H. M. (1953): The Normal Vascular Anatomy of the Femoral Head in Adult Man. Journal of Bone and Joint Surgery, 35-B, 442.

Trueta, J., and Little, K. (1960): The Vascular Contribution to Osteogenesis. II. Studies with the Electron Microscope. Journal of Bone and Joint Surgery, 42-B, 367.

Trueta, J., and Morgan, J. D. (1960): The Vascular Contribution to Osteogenesis. I. Studies by the Injection Method. Journal of Bone and Joint Surgery, 42-B, 97.

URist, M. R., and McLean, F. C. (1952): Osteogenetic Potency and New-bone Formation by Induction in Transplants to the Anterior Chamber of the Eye. Journal of Bone and Joint Surgery, 34-A, 443.

Vaes, G. M., and Nichols, G. (1962): Oxygen Tension and the Control of Bone Cell Metabolism. Nature, 193, 379.

WAUGH, W. (1958): The Ossification and Vascularisation of the Tarsal Navicular and their Relation to Köhler's Disease. Journal of Bone and Joint Surgery, 40-B, 765.

Wiley, A. M., and Trueta, J. (1959): The Vascular Anatomy of the Spine and its Relationship to Pyogenic Vertebral Osteomyelitis. Journal of Bone and Joint Surgery, 41-B, 796.

Willestaedt, H., Levander, G., and Hult, L. (1950): Studies in Osteogenesis. Acta Orthopaedica Scandinavica, $19,419$.

WolfF, J. (1870): Ueber die innere Architectur der Knochen und ihre Bedeutung für die Frage vom Knochenwachsthum. Archiv für pathologische Anatomie und Physiologie, 50, 389.

Young, R. W. (1962): Autoradiographic Studies on Nucleic Acid Metabolism and Protein Synthesis in the Cells of Bones. The Orthopaedic Research Society, Eighth Annual Meeting, Chicago.

Zucman, J. (1960): Studies on the Vascular Connexions between Periosteum, Bone, and Muscle. British Journal of Surgery, 48, 324. 